\title{
OS CIRCUITOS ESPACIAIS DA PRODUÇÃO DE COCO NO LITORAL OESTE DO CEARÁ
}

\author{
Leandro Vieira Cavalcante \\ Mestre em Geografia pela Université Paris 1 e pela Universidade Estadual do Ceará \\ leandro.cavalcante@hotmail.com
}

\begin{abstract}
RESUMO
Compreender como se organiza o circuito espacial da produção de coco no Litoral Oeste do Ceará é o objetivo principal deste trabalho. Para tanto, procura-se analisar e estabelecer relações entre as distintas etapas do seu processo produtivo, abarcando variados aspectos relacionados à produção agrícola, ao processamento industrial, à comercialização, à distribuição e ao consumo de coco. Ao elencar a categoria circuito espacial produtivo como basilar para o entendimento da configuração da produção de coco realizada no Litoral Oeste cearense, fornecem-se elementos fundamentais que auxiliam a apreensão do espaço geográfico da região em análise. Neste estudo foram privilegiados os municípios de Trairi, Itarema, Acaraú, Paraipaba, Itapipoca e Amontada, que estão entre os maiores produtores de coco do Ceará e do Brasil. Esses seis municípios configuram a região cearense mais dinâmica no que se refere ao cultivo de coco, com forte especialização territorial produtiva, onde o circuito espacial da produção do fruto assume maior relevância e se dá de forma mais intensa. A metodologia foi constituída especialmente por um levantamento de material bibliográfico, organização de séries estatísticas de variáveis e indicadores de interesse para a pesquisa, compilação de uma hemeroteca e realização de trabalhos de campo nos referidos municípios.
\end{abstract}

Palavras-chave: Cultivo de coco; Espaço e produção agrícola; Reestruturação produtiva da agricultura; Círculos de cooperação.

\section{CIRCUITO ESPACIAL DE LA PRODUCCIÓN DE COCO EN EL LITORAL OESTE DE CEARÁ}

\begin{abstract}
RESUMEN
El objetivo principal de este trabajo es comprender cómo se organiza el circuito espacial de la producción de coco en el Litoral Oeste de Ceará. De esta manera, se trata de analizar y establecer relaciones entre las diferentes etapas de su proceso productivo, abarcando diversos aspectos relacionados a la producción agrícola, el procesamiento industrial, la comercialización, la distribución y el consumo de coco. Al utilizar la categoría circuito espacial productivo como fundamento para comprender la configuración de la producción de coco del Litoral Oeste de Ceará, se presenta elementos para mejor comprender el espacio geográfico de esta región. Este estudio se centra en los municipios de Trairi, Itarema, Acaraú, Paraipaba, Itapipoca y Amontada, que están entre los mayores productores de coco de Ceará y de Brasil. Estos seis municipios configuran la región más dinámica de Ceará en referencia al cultivo de coco, con una fuerte especialización territorial productiva, donde el circuito espacial de la producción de esta fruta adquiere mayor importancia y se da con mayor intensidad. La metodología consistió especialmente por una recopilación bibliográfica, organización de series estadísticas de variables e indicadores de interés para la investigación, compilación de una hemeroteca y realización del trabajo de campo en las municipalidades.
\end{abstract}

Palabras-clave: Cultivo de coco; Espacio y producción agrícola; Reestructuración productiva de la agricultura; Círculos de cooperación.

Recebido em 26/06/2015

Aprovado para publicação em 06/11/2015

$\begin{array}{llllll}\text { Caminhos de Geografia } & \text { Uberlândia } & \text { v. 17, n. } 57 & \text { Mar/2016 } & \text { p. 41-58 } & \text { Página } 41\end{array}$




\section{INTRODUÇÃO}

Compreender como se organiza o circuito espacial da produção de coco do Litoral Oeste do Ceará é o objetivo principal deste trabalho ${ }^{2}$. Para tanto, procura-se analisar e estabelecer relações entre as distintas etapas do seu processo produtivo do fruto, abarcando variados aspectos relacionados à produção agrícola, ao processamento industrial, à comercialização, à distribuição e ao consumo de coco. Ao elencar a categoria "circuito espacial da produção" (SANTOS, 1986, 1994, 1996) como basilar para o entendimento da configuração da produção de coco realizada no Litoral Oeste cearense fornecem-se, também, elementos fundamentais que auxiliam numa melhor apreensão do espaço geográfico da região em análise.

Optou-se por apresentar essa região a partir da sua produção de coco justamente pela importância econômica que esse produto representa para os municípios aí localizados, uma vez que essa atividade não se pauta apenas na produção agrícola, e sim em um próprio e dinâmico circuito espacial produtivo, abrangendo também o segmento industrial e os setores de distribuição, comercialização e consumo. Juntas, todas essas atividades agem unindo, em um só movimento, diferentes parcelas do espaço nas quais elas são realizadas, chamadas por Santos (1985) de "instâncias produtivas", indispensáveis para um melhor entendimento do próprio espaço, entendido por esse autor como algo uno, total e invisível, constantemente reorganizado pelas atividades econômicas que aí se dão, a exemplo do cultivo de coco.

Nota-se, de um modo geral, que a produção desse fruto vem se expandindo por todo o país, em virtude especialmente de uma completa reorganização do setor observada com mais intensidade a partir do início dos anos 1990, período esse que coincide com o aumento da quantidade produzida e da área plantada nas principais regiões produtoras, como observado no Litoral Oeste cearense. Essa expansão vem reorganizando as principais dinâmicas socioespaciais e produtivas de tais regiões, além também de remodelar e prover de novas características o circuito espacial produtivo do fruto, dotado de novos conteúdos em virtude dessa reestruturação pela qual passa o setor do coco como um todo.

Neste estudo privilegiou-se os municípios de Trairi, Itarema, Acaraú, Paraipaba, Itapipoca e Amontada, que estão entre os maiores produtores de coco do Ceará e também do Brasil. $O$ conjunto desses seis municípios se caracteriza como a região cearense mais dinâmica no que se refere ao cultivo de coco, com forte especialização territorial produtiva, onde o circuito espacial da produção do fruto, assim como seus respectivos círculos de cooperação, assumem maior relevância e se dão de forma mais intensa, a ponto de influenciar de maneira bastante significativa as dinâmicas rurais e urbanas locais. Além disso, é nesses municípios onde se pode perceber com mais intensidade os rebatimentos da reestruturação produtiva do setor do coco na reorganização de seu circuito espacial produtivo.

Para evidenciar e analisar a organização do circuito espacial da produção de coco no Litoral Oeste do Ceará, a metodologia utilizada baseou-se em algumas importantes atividades inerentes à pesquisa científica, a saber: a) levantamento e leitura de material bibliográfico; b) levantamento e organização de séries estatísticas de variáveis e indicadores de interesse para a pesquisa; c) organização de uma hemeroteca; d) realização de trabalhos de campo. $O$ levantamento bibliográfico consistiu na reunião de diversos trabalhos que abordavam assuntos e temas diretamente relacionados à pesquisa, a exemplo da reestruturação produtiva da agricultura, dos circuitos espaciais produtivos e círculos de cooperação e da produção de coco. Já na organização de séries estatísticas montou-se um banco de dados com diversos indicadores quantitativos. Esses dados versam, sobretudo, sobre as produções agrícola e industrial, a comercialização, as exportações, o mercado e o consumo de coco, e foram obtidos em órgãos e instituições de pesquisa como o Instituto Brasileiro de Geografia e Estatística (IBGE), sobretudo através de consulta à base de dados da Produção Agrícola Municipal (PAM).

Outra atividade empreendida foi a formação de uma hemeroteca agregando várias reportagens jornalísticas acerca do circuito espacial da produção de coco, obtidas especialmente nos principais jornais, revistas e portais de notícia do Brasil e do Ceará que tratam sobre as

\footnotetext{
${ }^{2}$ Destaca-se que os resultados aqui apresentados são oriundos de desdobramentos do trabalho de conclusão de curso de Cavalcante (2012), realizado sob a orientação de Denise Elias, professora do Programa de Pós-graduação em Geografia da Universidade Estadual do Ceará.
}

$\begin{array}{llllll}\text { Caminhos de Geografia } & \text { Uberlândia } & \text { v. 17, n. } 57 & \text { Mar/2016 } & \text { p. 41-58 } & \text { Página } 42\end{array}$


atividades agrícolas de um modo geral e, sobretudo sobre o cultivo de coco. A realização dos trabalhos de campo nos seis municípios da região em análise foi outra atividade importante, ocorrida em 2011, que permitiu um melhor conhecimento da organização do setor do coco através da visita a inúmeros locais onde se desenvolviam atividades a ele relacionadas e do contato com os diferentes agentes envolvidos nas diversas etapas de seu circuito espacial produtivo, com os quais foram realizadas 75 entrevistas semiestruturadas, indispensáveis para o fornecimento de muitas das informações aqui apresentadas.

No presente artigo discute-se inicialmente a noção de circuito espacial produtivo, bem como sua intrínseca relação com o espaço geográfico. Em seguida apresentam-se as principais características inerentes à organização da produção de coco no Brasil e no Ceará, focando principalmente na reestruturação produtiva pela qual passa esse setor. $\mathrm{Na}$ sequência apresenta-se detalhadamente a configuração do circuito espacial produtivo do coco evidenciado no Litoral Oeste cearense, onde são indicadas as principais características relativas à produção, comercialização, processamento industrial, escoamento, distribuição e, por fim, consumo desse fruto.

\section{ESPAÇO E CIRCUITO ESPACIAL PRODUTIVO}

Santos (1999) assegura que todo ato produtivo é, obrigatoriamente, um ato de produção do espaço ${ }^{3}$. "Como produzir e produzir espaço são sinônimos, a cada novo modo de produção (ou a cada novo momento do mesmo modo de produção) mudam a estrutura e o funcionamento do espaço" (SANTOS, 1999, p. 06). Dessa forma, produzir e produzir espaço seriam dois atos indissociáveis, já que toda produção implicaria em modificações nas paisagens e em alterações na dinâmica de uso e organização do espaço. Ainda segundo com Santos (2008a), o espaço sempre foi o lócus da produção, já que sem produção não há espaço e vice-versa. $O$ autor vai afirmar também que uma das melhores possibilidades de apreensão da organização espacial a partir de uma determinada produção seria uma análise centrada nos seus circuitos espaciais produtivos (SANTOS, 1986).

Nesse sentido, a respeito dos circuitos espaciais da produção, Santos (1985, p. 03) assevera que como eles se dão no espaço, de forma desagregada, embora não desarticulada, a importância que as etapas produtivas têm a cada momento histórico e para cada caso particular ajuda, sobremaneira, na compreensão da organização desse espaço. Desse modo, somente através de uma análise que consiga abarcar todas as etapas produtivas é que se pode fornecer elementos que levam à apreensão da totalidade do espaço, já que são consideradas as relações e interações entre todas as instâncias produtivas, geograficamente dispersas (SANTOS, 1985). Reforça-se que, de acordo com Castillo e Frederico (2010, p. 463), essa noção de circuito espacial produtivo:

[...] enfatiza, a um só tempo, a centralidade da circulação (circuito) no encadeamento das diversas etapas da produção; a condição do espaço (espacial) como variável ativa na reprodução social; e o enfoque centrado no ramo, ou seja, na atividade produtiva dominante (produtivo) ${ }^{4}$.

Atualmente, as diversas relações e as trocas que se dão no interior das instâncias produtivas não se organizam mais de forma somente local, regional e/ou nacional, e sim de uma forma global. Por essa razão, de acordo com Santos (1994, p. 49), não se pode mais falar em circuitos regionais da produção, onde com "a crescente especialização regional, com os inúmeros fluxos de todos os tipos, intensidades e direções, temos que falar de circuitos espaciais da produção". Além disso, com a crescente dispersão espacial produtiva, tanto agrícola como industrial, os mercados consumidores estão se distanciando cada vez mais dos centros produtores, impondo a existência de meios que interliguem os espaços da produção aos espaços do consumo.

\footnotetext{
${ }^{3}$ Essa produção, conforme esclarece Santos (2008a), supõe uma intermediação entre o homem e a natureza, através das técnicas e dos instrumentos de trabalho inventados para o exercício desse intermédio.

${ }^{4}$ Castillo e Frederico (2010, p. 464-465) acrescentam também que "[...] os circuitos espaciais de produção pressupõem a circulação de matéria (fluxos materiais) no encadeamento das instâncias geograficamente separadas da produção, distribuição, troca e consumo, de um determinado produto, num movimento permanente".
}

$\begin{array}{llllll}\text { Caminhos de Geografia } & \text { Uberlândia } & \text { v. 17, n. } 57 & \text { Mar/2016 } & \text { p. 41-58 } & \text { Página } 43\end{array}$


Como a localização das diversas etapas do processo produtivo (produção propriamente dita, circulação, distribuição, consumo) pode doravante ser dissociada e autônoma, aumentam as necessidades de complementação entre lugares, gerando circuitos produtivos e fluxos cuja natureza, direção, intensidade e força variam segundo os produtores, segundo as formas produtivas, segundo a organização do espaço preexistente e os impulsos políticos (SANTOS, 1996, p. 128).

Com isso, se por um lado as diversas etapas da produção-distribuição-comercializaçãoconsumo se tornaram cada vez mais desagregadas no espaço, por outro lado estão cada vez mais articuladas devido à possibilidade do aumento das circulações materiais e imateriais (FREDERICO, 2010). Aqui, a circulação vai aparecer enquanto elemento-chave, já que não basta produzir, é preciso fazer essa produção circular, ou seja, "[...] é indispensável transformar as massas produzidas em fluxos" (SANTOS, 1985, p. 62). A esse respeito, Santos e Silveira (2003, p. 143, grifo do autor) esclarecem que

\begin{abstract}
[...] para entender o funcionamento do território é preciso captar o movimento, daí a proposta de abordagem que leva em conta os circuitos espaciais da produção. Estes são definidos pela circulação de bens e produtos e, por isso, oferecem uma visão dinâmica, apontando a maneira como os fluxos perpassam o território.
\end{abstract}

E esses fluxos aos quais se referem os autores não são obrigatoriamente materiais, podendo ser também fluxos imateriais, como capitais, informações, mensagens, ordens, entre outros, que compõem o que Santos (1996) vai chamar de "círculos de cooperação", estando sempre associados aos circuitos espaciais de produção. "Essa seria a inteligência do capital, reunindo o que o processo direto da produção havia separado em diversas empresas e lugares, mediante o aparecimento de verdadeiros círculos de cooperação", conforme elucidam Santos e Silveira (2003, p. 144). Ainda a esse respeito, para Frederico (2010) foi a difusão desses fluxos imateriais uma das principais responsáveis pelo aprofundamento da divisão territorial do trabalho e ampliação dos circuitos espaciais produtivos.

Assim, a apreensão do uso e da organização do espaço pelas atividades produtivas, como 0 cultivo de coco, pode ser vislumbrada a partir da análise de seu circuito espacial de produção e seus respectivos círculos de cooperação, mostrando, antes de mais nada, como tais atividades agem na dinamização do espaço onde todas elas são realizadas. Isso levaria, ainda, a compreender também o "[...] uso diferenciado de cada território por parte das empresas, das instituições, dos indivíduos e permitem compreender a hierarquia dos lugares desde a escala regional até a escala mundial" (SANTOS e SILVEIRA, 2003, p. 144).

De acordo com Elias (2003, p. 141), para estudar os circuitos espaciais e os círculos de cooperação de um determinado produto, é necessário "[...] considerar todas as relações técnicas e econômicas envolvidas, assim como a interação entre elas". Em um primeiro momento devem-se elencar todos os seus elementos constituintes e todas suas variáveis empíricas e, num segundo estágio, descrever e interpretar todas suas conexões e interações para que seja possível apreender os circuitos espaciais da produção e os círculos de cooperação em seu conjunto, como sugerem Aracri e Moreira (2010). Desse modo, na sequência são apresentadas as principais etapas que compõem particularmente o circuito espacial da produção de coco no Litoral Oeste, sem esquecer de seus respectivos círculos de cooperação, já que ambos estão intimamente interligados. Antes disso, é importante indicar primeiramente a atual configuração do cultivo desse fruto no Brasil e no Ceará.

\title{
A ATUAL CONFIGURAÇÃO DA PRODUÇÃO DE COCO NO BRASIL/CEARÁ
}

A agricultura brasileira passa por uma significativa reestruturação produtiva desde meados da década de 1970, conforme assegura Elias (2003). A partir dessa época, o espaço agrário do país passa a receber com mais intensidade uma influência direta da tecnologia, da ciência e da informação, signos do atual período histórico, chamado por Santos $(1996,2009)$ de técnicocientífico-informacional, que tem na globalização da produção e do consumo um de seus pilares fundamentais (ELIAS, 2003). Essa reestruturação da agricultura brasileira é marcada

$\begin{array}{llllll}\text { Caminhos de Geografia } & \text { Uberlândia } & \text { v. 17, n. } 57 & \text { Mar/2016 } & \text { p. 41-58 } & \text { Página } 44\end{array}$


especialmente por uma modernização do processo produtivo agrícola, pela ocupação de novas regiões com cultivos que apresentem uma alta rentabilidade financeira, pela integração de capitais e difusão do modelo produtivo do agronegócio, pelo aumento do controle dos processos de trabalho, entre outros. Tudo isso acaba por culminar em uma reorganização dos principais circuitos espaciais produtivos agrícolas do país, que passam a ser regulados cada vez mais por agentes hegemônicos e exógenos ao local da produção, contribuindo para a ampliação da reprodução do grande capital também no campo.

Essa reestruturação produtiva, além de se dar espacialmente seletiva e socialmente excludente (ELIAS, 2006), vai privilegiar somente determinados gêneros agrícolas, os quais têm seu processo produtivo totalmente reorganizado com a finalidade de auferir uma maior rentabilidade ao capital. Entre esses gêneros agrícolas destaca-se o coco. No cultivo desse fruto, tal reestruturação produtiva se dá de maneira bastante particular e vem afetando radicalmente as forças produtivas no setor a ponto de inaugurar novas formas de se produzir e de reorganizar todo o seu circuito espacial de produção, especialmente nestas duas últimas décadas. Com isso, observa-se nos coqueirais brasileiros uma crescente difusão do modo de produção capitalista baseado em preceitos da agricultura científica e do agronegócio globalizado em detrimento da redução significativa das formas pré-capitalistas de produção, especialmente aquelas associadas ao extrativismo vegetal, característica basilar do cultivo de coco até bem pouco tempo atrás, como demonstrado em Cavalcante $(2014,2015)$.

Assim, a reestruturação produtiva do setor do coco pode ser caracterizada, entre inúmeros processos, por uma acelerada difusão de várias inovações e pela incorporação de novas tecnologias ao processo produtivo do fruto, com a utilização de novos e modernos insumos na produção. Há uma propagação de novos métodos de irrigação, como as práticas de irrigação localizada, totalmente automatizada, representada pelos microaspersores, onde cada coqueiro é irrigado individualmente e recebe uma quantidade exata de água. Além disso, há uma difusão no uso de técnicas de adubação que garantem uma maior precisão e uma maior produtividade, sendo a mais comum a técnica de fertirrigação, em que cada coqueiro vai receber uma quantidade predeterminada de fertilizantes diluídos na água e aplicada pelos microaspersores. Há ainda um aumento importante do cultivo de coqueiros híbridos, que são geneticamente melhorados e apontados como mais resistentes às pragas.

Associado a essa modernização do processo produtivo desse fruto está também o aumento considerável de seu consumo, sobretudo da água, advinda do coco colhido ainda verde. A expansão do consumo de água de coco, seja in natura seja processada, cresce a cada dia, especialmente em razão do aumento da demanda por produtos ditos mais saudáveis e com baixas calorias, responsável por alavancar a busca por essa água em todo o país, mormente na região Sudeste, que hoje concentra o maior mercado consumidor desse produto. Segundo destacam Cavalcanti et al. (2006), isso tem motivado novos produtores a se aventurarem na produção do fruto, cultivando basicamente a variedade de coqueiro anão, a mais recomendada para a produção de coco verde.

Em virtude da associação desses dois processos - modernização do processo produtivo e boom do consumo de água de coco -, além de vários outros, a produção brasileira de coco vem aumentando consideravelmente desde 1990, bem como a área plantada e a produtividade. Conforme apontam os dados do IBGE (Tabelas 1 e 2), de 1990 a 2010 a quantidade produzida com coco no Brasil teve um expressivo aumento de $158 \%$, chegando aos quase dois bilhões de frutos, quantidade muito superior à observada nos anos 1990, transformando o país no quarto maior produtor mundial de coco, segundo a Organização das Nações Unidas para Alimentação e Agricultura $(F A O)^{5}$. Já a área plantada com coqueiros acompanhou o aumento da produção, porém mais modestamente, tendo um crescimento de aproximadamente $28 \%$, demonstrando que há uma expansão do cultivo de coqueiros em território brasileiro, especialmente em locais que anteriormente não produziam o fruto em escala comercial, a exemplo do interior do Nordeste e do Centro-sul do país. Associada ao aumento da área plantada e da quantidade produzida, a produtividade também obteve um

\footnotetext{
${ }^{5}$ Ainda de acordo com os dados da FAO, em 1990 o Brasil ocupava apenas o décimo lugar no ranking mundial de produção de coco.
}

$\begin{array}{llllll}\text { Caminhos de Geografia } & \text { Uberlândia } & \text { v. 17, n. } 57 & \text { Mar/2016 } & \text { p. 41-58 } & \text { Página } 45\end{array}$


crescimento importante, atestando para a eficiência da modernização do processo produtivo do fruto, sobretudo com a difusão de novos sistemas de irrigação, onde passou-se a produzir mais sem, necessariamente, ampliar sobremaneira a área plantada.

Tabela 1. Área plantada, quantidade produzida e produtividade de coco no Brasil, de 1990 a 2010.

\begin{tabular}{l|ccc}
\hline & $\mathbf{1 9 9 0}$ & $\mathbf{2 0 0 0}$ & $\mathbf{2 0 1 0}$ \\
\hline Área plantada (hectares) & 215.652 & 266.577 & 276.934 \\
Quant. Produzida (mil frutos) & 734.418 & 1.301 .411 & 1.895 .635 \\
Produtividade (mil frutos/ha) & 3,41 & 4,88 & 6,85 \\
\hline
\end{tabular}

Fonte: IBGE/PAM (2010).

Tabela 2. Área plantada, quantidade produzida e produtividade de coco no Brasil, de 1990 a 2010. Variações absoluta e relativa (em \%).

\begin{tabular}{l|ccc|ccc}
\hline & \multicolumn{3}{|c|}{ Variação Absoluta } & \multicolumn{3}{c}{ Variação Relativa } \\
\cline { 2 - 7 } & $\mathbf{1 9 9 0 -}$ & $\mathbf{2 0 0 0 -}$ & $\mathbf{1 9 9 0 -}$ & $\mathbf{1 9 9 0}-$ & $\mathbf{2 0 0 0}-$ & $\mathbf{1 9 9 0}-$ \\
& $\mathbf{2 0 0 0}$ & $\mathbf{2 0 1 0}$ & $\mathbf{2 0 1 0}$ & $\mathbf{2 0 0 0}$ & $\mathbf{2 0 1 0}$ & $\mathbf{2 0 1 0}$ \\
\hline Área plantada & 50.925 & 10.357 & 61.282 & 23,61 & 3,89 & 28,42 \\
Quant. produzida & 566.993 & 594.224 & 1.161 .217 & 77,20 & 43,57 & 158,11 \\
Produtividade & 1,48 & 1,96 & 3,44 & 43,35 & 40,21 & 101,00 \\
\hline
\end{tabular}

Fonte: IBGE/PAM (2010).

Outra característica da reestruturação produtiva do setor do coco no Brasil é a dispersão geográfica dessa produção, com um avanço da fronteira agrícola do fruto em direção ao semiárido nordestino e em direção às demais regiões do país, sobretudo Norte e Sudeste, desconcentrando o cultivo historicamente localizado no litoral da região Nordeste. Mas mesmo com essa dispersão da produção para outras regiões, o Nordeste continua sendo o maior produtor do fruto no Brasil, concentrando atualmente por volta de $68 \%$ da quantidade produzida e $81 \%$ da área cultivada. Em 2010, de acordo com os dados do IBGE, os maiores produtores nacionais de coco foram, respectivamente, Bahia, há séculos a principal produtora do fruto, seguida de Ceará, Sergipe, Pará e Espírito Santo, que juntos concentravam $74 \%$ de todo 0 coco cultivado no país.

O estado do Ceará se insere nesse contexto de forma bastante peculiar, visto que se configura, atualmente, como o segundo maior produtor do fruto do país, possuindo também a segunda maior área plantada com coqueiros. Assim como o setor do coco no Brasil vem passando por uma reestruturação produtiva, na produção cearense também é possível observar o desenrolar de processos que caracterizam essa reestruturação do setor, que acarretam uma série de modificações em todo o seu circuito espacial produtivo. Até mesmo no Ceará as práticas extrativistas que se davam na produção de coco foram alteradas, e em alguns casos até deixaram de ser praticadas, e hoje seu cultivo está permeado de relações tipicamente capitalistas e cada vez mais aberto a determinações exógenas ao local da produção (CAVALCANTE, 2015).

Assim como observado no contexto brasileiro, analisando os dados divulgados pela PAM/IBGE, percebe-se que de 1990 a 2010 a produção cearense de coco praticamente dobrou, obtendo um aumento de $99 \%$, enquanto a área plantada cresceu quase $25 \%$ e a produtividade $60 \%$, como representado nas tabelas abaixo (Tabelas 3 e 4). Esses indicadores demonstram que a produção do fruto no Ceará teve um importante impulso nestas últimas duas décadas, atestando ainda para uma produtividade em ascensão, como resultado, sobretudo de uma completa racionalização do seu cultivo em virtude da materialização da reestruturação produtiva em curso, que vem alterando consideravelmente a geografia cearense da produção de coco (CAVALCANTE, 2015). Destaca-se que em 2010 o Ceará concentrava 14\% da produção nacional e 16\% da área plantada no país.

Tabela 3. Área plantada, quantidade produzida e produtividade de coco no Ceará, de 1990 a 2010.

\begin{tabular}{l|ccc}
\hline & $\mathbf{1 9 9 0}$ & $\mathbf{2 0 0 0}$ & $\mathbf{2 0 1 0}$ \\
\hline Área plantada (hectares) & 35.431 & 37.316 & 44.224 \\
Quant. Produzida (mil frutos) & 133.880 & 193.729 & 266.263 \\
Produtividade (mil frutos/ha) & 3,78 & 5,19 & 6,02 \\
\hline
\end{tabular}

Fonte: IBGE/PAM (2010)

$\begin{array}{llllll}\text { Caminhos de Geografia } & \text { Uberlândia } & \text { v. 17, n. } 57 & \text { Mar/2016 } & \text { p. 41-58 } & \text { Página } 46\end{array}$


Tabela 4. Área plantada, quantidade produzida e produtividade de coco no Ceará, de 1990 a 2010.

\begin{tabular}{l|ccc|ccc}
\hline & \multicolumn{3}{|c|}{ Variação Absoluta } & \multicolumn{3}{c}{ Variação Relativa } \\
\cline { 2 - 7 } & $\mathbf{1 9 9 0 -}$ & $\mathbf{2 0 0 0 -}$ & $\mathbf{1 9 9 0 -}$ & $\mathbf{1 9 9 0 -}$ & $\mathbf{2 0 0 0}-$ & $\mathbf{1 9 9 0 -}$ \\
& $\mathbf{2 0 0 0}$ & $\mathbf{2 0 1 0}$ & $\mathbf{2 0 1 0}$ & $\mathbf{2 0 0 0}$ & $\mathbf{2 0 1 0}$ & $\mathbf{2 0 1 0}$ \\
\hline Área plantada & 1.885 & 6.908 & 8.793 & 5,32 & 19,50 & 24,82 \\
Quant. produzida & 59.849 & 72.534 & 132.383 & 44,70 & 37,44 & 98,88 \\
Produtividade & 1,41 & 0,83 & 2,24 & 37,39 & 15,97 & 59,34 \\
\hline
\end{tabular}

Fonte: IBGE/PAM (2010).

No Ceará, 170 de seus 184 municípios produzem coco, reafirmando a importância que o cultivo do fruto tem em território cearense. No entanto, toda essa produção é espacialmente concentrada em alguns poucos municípios, onde o cultivo de coco é altamente dinâmico e se configura como um dos principais cultivos agrícolas aí realizados, movimentando a economia local. Como se pode observar na tabela abaixo (Tabela 5), somente 10 municípios concentravam em 2010 aproximadamente $71 \%$ da área plantada com coqueiros e $64 \%$ da produção total de coco no Ceará, demonstrando o peso que possuem na configuração produtiva do fruto no estado, atestando ainda a existência de uma considerável especialização no cultivo desse fruto. Tais municípios se localizam ao longo de todo o litoral cearense (divido entre Leste e Oeste, tomando como referência a cidade de Fortaleza) e no vale dos rios Curu e Acaraú, sobretudo em perímetros irrigados federais aí instalados.

Tabela 5. Participação (em \%) dos principais municípios produtores de coco em relação ao total produzido no Ceará, em 2010.

\begin{tabular}{r|c|c|c|c}
\hline & $\begin{array}{c}\text { Quantidade } \\
\text { Produzida }\end{array}$ & Ranking & $\begin{array}{c}\text { Área } \\
\text { Plantada }\end{array}$ & Ranking \\
\hline Trairi & 12,05 & $1^{\circ}$ & 16,13 & $1^{\circ}$ \\
Acaraú & 8,59 & $2^{\circ}$ & 11,33 & $3^{\circ}$ \\
Itarema & 8,23 & $3^{\circ}$ & 12,42 & $2^{\circ}$ \\
Paraipaba & 6,31 & $4^{\circ}$ & 3,08 & $11^{\circ}$ \\
Itapipoca & 5,58 & $5^{\circ}$ & 8,31 & $4^{\circ}$ \\
Beberibe & 5,42 & $6^{\circ}$ & 5,31 & $5^{\circ}$ \\
Pentecoste & 5,01 & $7^{\circ}$ & 2,92 & $12^{\circ}$ \\
Amontada & 4,98 & $8^{\circ}$ & 5,05 & $6^{\circ}$ \\
Camocim & 3,96 & $9^{\circ}$ & 3,13 & $10^{\circ}$ \\
Cascavel & 3,95 & $10^{\circ}$ & 3,72 & $7^{\circ}$ \\
\hline Total & 64,08 & - & 71,40 & - \\
\hline \multicolumn{5}{c}{ Fonte: IBGE/PAM (2010). }
\end{tabular}

Desses 10 municípios, seis formam uma importante região contínua de produção de coco, que é realizada ao longo de toda a costa, no interior desses municípios e nos perímetros irrigados existentes no vale de seus principais rios. Essa região, chamada neste trabalho apenas de Litoral Oeste, é formada pelos municípios de Acaraú, Amontada, Itarema, Itapipoca, Paraipaba e Trairi, localizados na figura a seguir (Figura 1).

Figura 1. Localização dos municípios que compõem o Litoral Oeste, a principal região de produção de coco do Ceará.

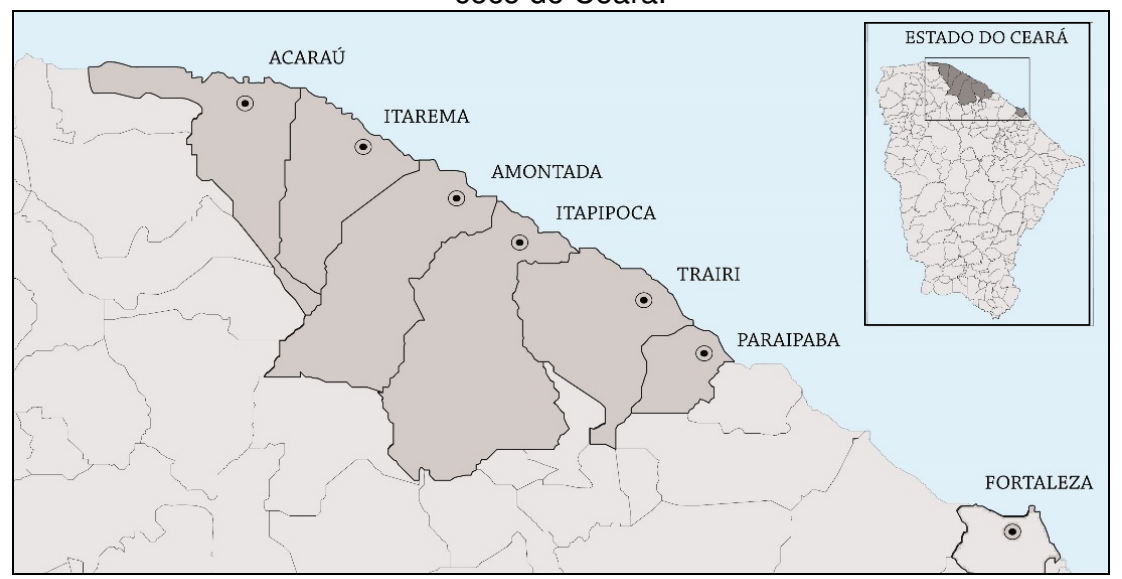

Fonte: Cavalcante (2015).

$\begin{array}{llllll}\text { Caminhos de Geografia } & \text { Uberlândia } & \text { v. 17, n. } 57 & \text { Mar/2016 } & \text { p. 41-58 } & \text { Página } 47\end{array}$


É a região mais dinâmica no que se refere ao cultivo do fruto no Ceará, concentrando $56 \%$ da área plantada com coqueiros e em torno de $46 \%$ de todo o coco produzido em 2010 . Nota-se no Litoral Oeste a existência de uma importante "especialização territorial produtiva" (SANTOS e SILVEIRA, 2003) ${ }^{6}$, centrada no cultivo desse fruto, muito em razão das condições técnicas e sociais que ela apresenta.

No Litoral Oeste encontram-se as maiores e principais fazendas e empresas agrícolas de produção de coco do Ceará, um total de sete grandes e médias empresas agroindustriais especializadas na fabricação de derivados do fruto, duas importantes empresas de pesquisa agrícola que desenvolvem estudos relacionados a melhoramento genético de coqueiros e técnicas de cultivo, além de uma articulada rede de intermediários que atuam na comercialização do coco e de centenas de pequenos, médios e grandes produtores que cultivam o fruto. Não por menos, observa-se nessa região a existência de um completo e dinâmico circuito espacial produtivo de coco, e esse cultivo é, de longe, uma das principais atividades econômicas realizadas em todos esses seis municípios, cada vez mais especializados.

\section{DA PRODUÇÃO AO CONSUMO: O CIRCUITO ESPACIAL PRODUTIVO DO COCO}

\section{PRODUÇÃO DE COCO PROPRIAMENTE DITA}

Nos seis municípios que formam a região em análise observa-se, a partir dos dados indicados na tabela seguinte (Tabela 6), que a produção de coco vem obtendo um expressivo crescimento em Paraipaba, Acaraú, Trairi e Itarema, ao passo da redução desse cultivo em Amontada e Itapipoca. No entanto, ao considerar o Litoral Oeste como um todo, nota-se que a área plantada com o fruto obteve um crescimento de 64\% em apenas 20 anos, índice esse muito maior do que o observado quando se considera todo o Ceará. Associado a isso está o aumento da quantidade produzida, que praticamente dobrou no mesmo período. Isso se deve sobremodo à expansão do cultivo de coco em Paraipaba, Acaraú e Itarema, que alavancou a quantidade produzida e a área plantada no Litoral Oeste, especialmente em virtude da introdução de novas tecnologias ao processo produtivo do fruto, ampliando a produtividade, e em razão do considerável aumento do consumo de água de coco, que levou novos produtores a investirem no cultivo de coqueiros, sobretudo anões.

Tabela 6. Área plantada e quantidade produzida com coco pelos municípios do Litoral Oeste do Ceará, de 1990 a 2010. Variações absoluta e relativa (em \%).

\begin{tabular}{|c|c|c|c|c|c|}
\hline & & 1990 & 2010 & $\begin{array}{l}\text { Variação } \\
\text { Absoluta }\end{array}$ & $\begin{array}{l}\text { Variação } \\
\text { Relativa }\end{array}$ \\
\hline Acaraú & $\begin{array}{l}\text { Área plantada } \\
\text { Quant. produzida }\end{array}$ & $\begin{array}{l}1.500 \\
7.500\end{array}$ & $\begin{array}{c}5.010 \\
22.881\end{array}$ & $\begin{array}{c}3.510 \\
15.381 \\
\end{array}$ & $\begin{array}{l}234,00 \\
205,08 \\
\end{array}$ \\
\hline Amontada & $\begin{array}{l}\text { Área plantada } \\
\text { Quant. produzida }\end{array}$ & $\begin{array}{c}2.500 \\
12.500\end{array}$ & $\begin{array}{c}2.235 \\
13.263 \\
\end{array}$ & $\begin{array}{l}-265 \\
763 \\
\end{array}$ & $\begin{array}{c}-10,60 \\
6,10 \\
\end{array}$ \\
\hline Itapipoca & $\begin{array}{l}\text { Área plantada } \\
\text { Quant. produzida }\end{array}$ & $\begin{array}{l}5.000 \\
17.400\end{array}$ & $\begin{array}{c}3.675 \\
14.860\end{array}$ & $\begin{array}{l}-1.325 \\
-2.540\end{array}$ & $\begin{array}{l}-26,50 \\
-14,60\end{array}$ \\
\hline Itarema & $\begin{array}{l}\text { Área plantada } \\
\text { Quant. produzida }\end{array}$ & $\begin{array}{l}2.000 \\
7.500\end{array}$ & $\begin{array}{c}5.493 \\
21.902\end{array}$ & $\begin{array}{c}3.493 \\
14.402\end{array}$ & $\begin{array}{l}174,65 \\
192,03\end{array}$ \\
\hline Paraipaba & $\begin{array}{l}\text { Área plantada } \\
\text { Quant. produzida }\end{array}$ & $\begin{array}{l}170 \\
850\end{array}$ & $\begin{array}{c}1.362 \\
16.806 \\
\end{array}$ & $\begin{array}{c}1.192 \\
15.956 \\
\end{array}$ & $\begin{array}{c}701,18 \\
1877,18 \\
\end{array}$ \\
\hline Trairi & $\begin{array}{l}\text { Área plantada } \\
\text { Quant. produzida }\end{array}$ & $\begin{array}{c}4.000 \\
16.000 \\
\end{array}$ & $\begin{array}{c}7.132 \\
32.074 \\
\end{array}$ & $\begin{array}{c}3.132 \\
16.074 \\
\end{array}$ & \begin{tabular}{|c|}
78,30 \\
100,46 \\
\end{tabular} \\
\hline LITORAL OESTE & $\begin{array}{l}\text { Área plantada } \\
\text { Quant. produzida }\end{array}$ & $\begin{array}{l}15.170 \\
61.750 \\
\end{array}$ & $\begin{array}{c}24.907 \\
121.786 \\
\end{array}$ & $\begin{array}{r}9.737 \\
60.036 \\
\end{array}$ & $\begin{array}{l}64,19 \\
97,22 \\
\end{array}$ \\
\hline CEARÁ & $\begin{array}{l}\text { Área plantada } \\
\text { Quant. produzida }\end{array}$ & $\begin{array}{c}35.431 \\
133.880\end{array}$ & $\begin{array}{c}44.224 \\
266.263\end{array}$ & $\begin{array}{c}8.793 \\
132.383\end{array}$ & $\begin{array}{l}24,82 \\
98,88\end{array}$ \\
\hline
\end{tabular}

Fonte: IBGE/PAM (2010).

Todo esse coco é cultivado tanto em pequenas como em médias e grandes propriedades. De um modo geral, conforme observado nos trabalhos de campo, a grande maioria dos

\footnotetext{
${ }^{6}$ As especializações territoriais produtivas, nos termos de Santos e Silveira (2003), expressam sobremodo uma concentração geográfica das atividades que perpassam um determinado circuito espacial produtivo, não se resumindo apenas à produção agrícola em si.
}

$\begin{array}{llllll}\text { Caminhos de Geografia } & \text { Uberlândia } & \text { v. 17, n. } 57 & \text { Mar/2016 } & \text { p. 41-58 } & \text { Página } 48\end{array}$


estabelecimentos produtores de coco no Litoral Oeste possui até 10 hectares. No entanto, há também vários latifúndios monocultores, que chegam a medir quase três mil hectares contínuos plantados exclusivamente com coqueiros, somando 100 mil pés. Apesar disso, mesmo com a presença dessas grandes fazendas, é notável que a maior parte dos estabelecimentos que produzem coco é representada por pequenas e médias propriedades, geridas especialmente por agricultores familiares que têm no cultivo do fruto um de seus principais rendimentos.

Em todos os seis municípios do Litoral Oeste realiza-se o cultivo de coqueiros gigante, anão e híbrido, onde a concentração dessas três variedades depende muito do município e da proximidade com o litoral. O cultivo da variedade gigante (Figura 2) é o que menos cresce, visto que ela demora muito para começar a produzir e a produtividade não é tão elevada. Os plantios de coqueiro gigante estão localizados principalmente nas regiões litorâneas, em áreas de dunas e restingas próximas à praia, muito cultivados ainda em moldes semiextensivos, com uma rarefeita aplicação de adubos, por exemplo. Itapipoca e Amontada são os municípios onde o cultivo dessa variedade de coqueiro é mais expressivo, razão pela qual a produção local de coco vem sendo progressivamente reduzida.

Já o cultivo de coqueiro anão (Figura 3) é, de longe, o que mais cresce em todo o Litoral Oeste. Vários são os produtores que estão substituindo antigos plantios e começando a cultivar exclusivamente coqueiro anão ${ }^{7}$, como foi relatado durante os trabalhos de campo. Tais produtores informaram que estão investindo no cultivo de coco em virtude especialmente das grandes possibilidades de um maior retorno financeiro, devido ao aumento do consumo de água de coco. Além disso, o coqueiro anão, voltado para a produção de coco verde, fornece uma produção mensal, garantindo um rendimento contínuo aos seus produtores. $\mathrm{O}$ mesmo pode se dizer dos coqueiros híbridos, também em ampla expansão no Litoral Oeste, sobretudo nas maiores fazendas aí instaladas. Destaca-se que tanto o coqueiro anão quanto o híbrido exigem cuidados constantes, impondo uma irrigação localizada diária para fornecer água para as árvores e uma aplicação de adubos e fertilizantes a cada mês.

Figura 2. Cultivo de coqueiro gigante em Itarema/CE

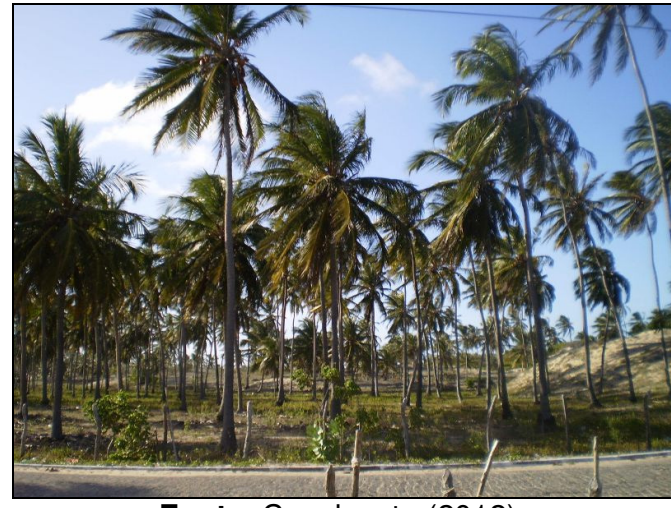

Fonte: Cavalcante (2012).
Figura 3. Cultivo de coqueiro anão em Paraipaba/CE

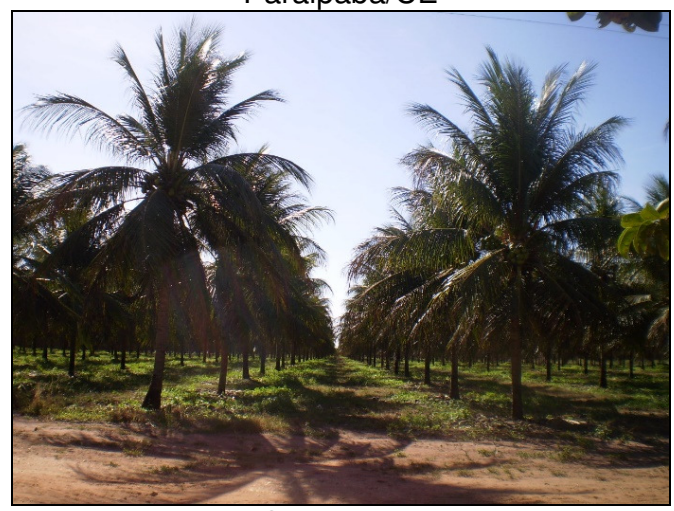

Fonte: Cavalcante (2012).

Essa exigência mensal da utilização de adubos, fertilizantes e implementos agrícolas nos cultivos de coqueiro anão e híbrido favorece, sobremaneira, a expansão do consumo produtivo relacionado ao cultivo de coco. Dessa forma, é importante atentar para o fato de que antes da produção agrícola propriamente dita uma série de atividades são realizadas visando dar suporte a esse cultivo. Observa-se que a reestruturação do setor do coco ampliou consideravelmente a necessidade da aquisição desses insumos que anteriormente eram inexistentes e que agora se tornaram indispensáveis, cujo uso influi de maneira substancial na produtividade dos coqueirais, fazendo, dessa forma, com que o "consumo produtivo agrícola" (ELIAS, 2006) também se faça presente no cultivo do fruto ${ }^{8}$.

\footnotetext{
${ }^{7}$ Entre esses outros produtos que estão perdendo espaço para o coco estão, principalmente: banana, caju/castanha, cana-de-açúcar e mamão.

${ }^{8}$ Ressalta-se que esse consumo produtivo agrícola precede à produção propriamente dita, podendo ser visto como a primeira das etapas que compõem um circuito espacial produtivo.
}

$\begin{array}{llllll}\text { Caminhos de Geografia } & \text { Uberlândia } & \text { v. 17, n. } 57 & \text { Mar/2016 } & \text { p. 41-58 } & \text { Página } 49\end{array}$


Santos (1996) assegura que o consumo produtivo cria uma demanda heterogênea segundo os espaços, onde os equipamentos mercantis tendem a ser diferentes de acordo com as necessidades de cada produto. Assim, determinados estabelecimentos acabam se especializando em comercializar insumos destinados a atender demandas específicas desse produto. Há nas áreas urbanas dos municípios do Litoral Oeste uma série de lojas que vendem insumos agrícolas dos mais diversos tipos e utilidades, especialmente material para irrigação, adubos, fertilizantes, agrotóxicos e maquinário agrícola. Essas lojas suprem as necessidades imediatas dos produtores de coco e agem como importantes fixos que compõem o circuito espacial produtivo do fruto.

Quando não são fabricados no próprio Ceará, principalmente na Grande Fortaleza, os insumos agrícolas comercializados nessas lojas e consumidos pelos produtores de coco originam-se de outros estados do Brasil, sendo adquiridos pelas lojas que vendem esses produtos diretamente com os fabricantes ou com seus respectivos representantes. Essa "produção para a produção" (SILVA, 2003) é controlada por empresas que se localizam em alguns poucos estados, especialmente das regiões Sul e Sudeste. No mapa a seguir (Figura 4), vislumbra-se o fluxo desses insumos e quais os estados que fornecem fertilizantes, agrotóxicos, máquinas agrícolas e material para irrigação, indicando que o Litoral Oeste funciona também enquanto um ponto na rede nacional de distribuição desses insumos e implementos agrícolas utilizados na produção de coco, em especial no cultivo de coqueiro anão e híbrido.

Figura 4. Origem dos insumos e implementos agrícolas adquiridos pelos produtores de coco do Litoral

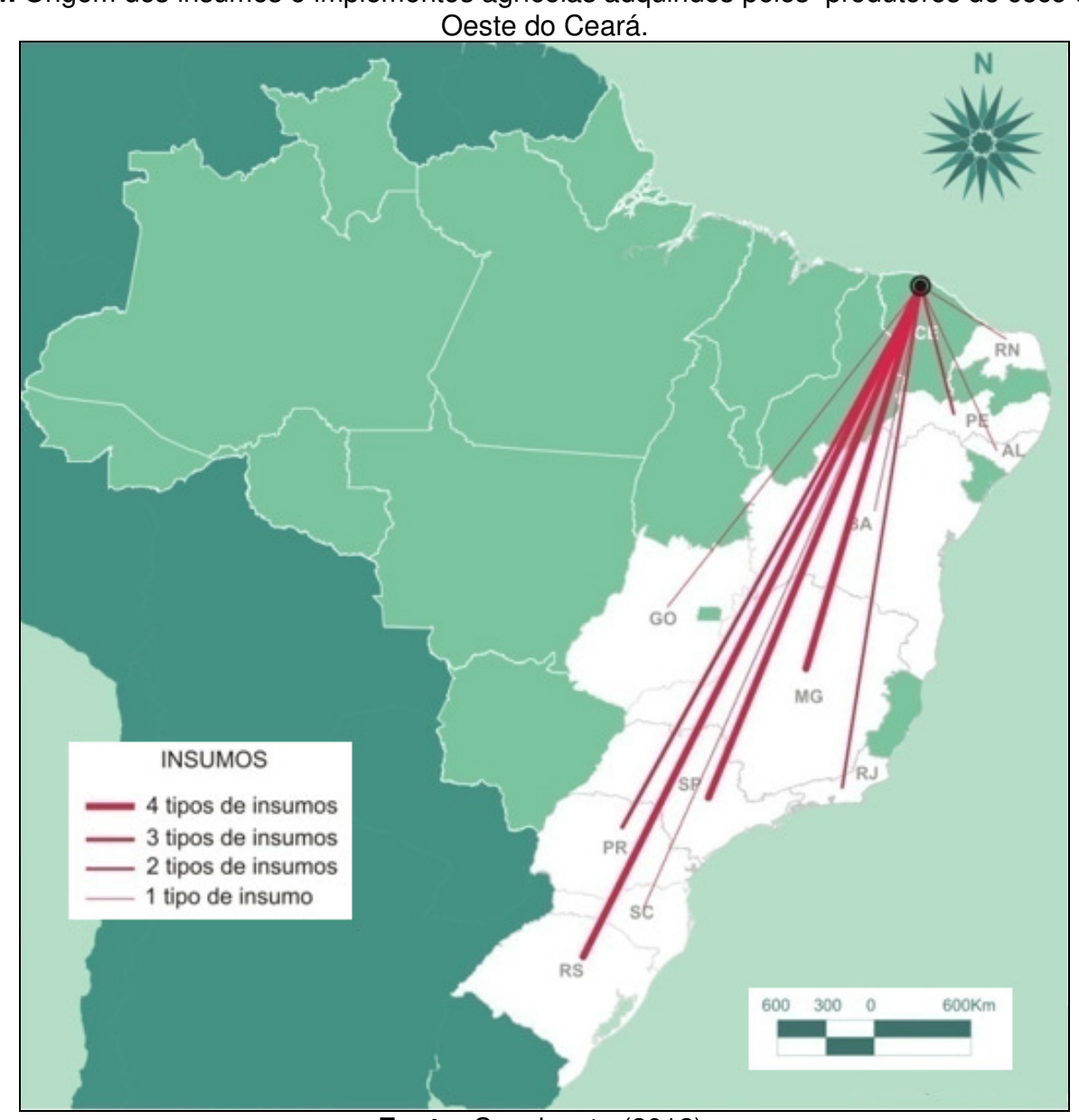

Fonte: Cavalcante (2012).

Associado à difusão desses insumos materiais está o importante papel da pesquisa científica voltada para o cultivo de coco. Observa-se que em diversas etapas do processo produtivo do fruto a pesquisa científica se faz presente, sendo visível a crescente inserção da tecnologia, ciência e informação nesse cultivo. Essa pesquisa científica direcionada à agricultura foi, e

\begin{tabular}{|c|}
\hline Caminhos de Geografia \\
\hline
\end{tabular}


ainda é, um importante instrumento indutor da reestruturação produtiva de diversos gêneros agrícolas no Brasil, entre eles o coco. Com a pesquisa científica foi possível reestruturar o conjunto de elementos técnicos empregados na agricultura, conforme aponta Elias (2003, p. 60), "[...] transformando os tradicionais sistemas agrícolas e abrindo novas e inúmeras possibilidades à realização da mais-valia mundializada, por meio de um processo de fusão de capitais com os demais setores econômicos".

Em todo o Brasil, o órgão que mais se destaca em pesquisas com coco é a Empresa Brasileira de Pesquisa Agropecuária (Embrapa), que desde a década de 1980 tem uma participação expressiva no que tange às pesquisas realizadas com o fruto, desenvolvendo uma série de experimentos e incorporando novas tecnologias ao seu processo produtivo. Uma das unidades criadas pela Embrapa e especializadas em pesquisas com coco é a Embrapa Tabuleiros Costeiros, localizada em Aracaju (SE), originada a partir do Centro Nacional de Pesquisa de Coco (CNPCo), criado em 1985 e que coordenava até então toda a pesquisa relacionada com o cultivo do fruto no Brasil. Atualmente, a Embrapa Tabuleiros Costeiros assume a liderança das pesquisas com coco no país, tornando-se uma grande referência para os estudos com 0 fruto e revolucionando por completo seu processo produtivo.

Outra unidade da Embrapa que realiza pesquisas com o coco é a Embrapa Agroindústria Tropical, localizada em Fortaleza (CE), onde são elaborados vários estudos com produtos de origem tropical, entre eles o coco. A Embrapa Agroindústria Tropical possui uma atuação direta no Litoral Oeste, especialmente por possuir uma unidade experimental nessa região, instalada em Paraipaba, onde há o coqueiral em que foram realizados os experimentos in loco de suas pesquisas, especialmente nas áreas de melhoramento genético e de sistemas de irrigação automatizada para coqueiros anões. Em diversos pontos do Litoral Oeste essa unidade da Embrapa realiza algumas atividades de extensão, como controle de pragas nos coqueirais, oficinas com produtores, consultorias em empresas agroindustriais que processam e exportam água de coco, entre outras.

Além dos estudos realizados por essas duas unidades da Embrapa, há também empresas privadas dedicadas à pesquisa com coco. No Litoral Oeste está instalada uma dessas empresas, que por sinal é uma das maiores do Brasil. Trata-se da Cohibra, especializada no desenvolvimento de tecnologias para a fabricação de coqueiros híbridos, cujas fazendas estão localizadas em Amontada. Essa empresa começou suas atividades com o melhoramento genético de mudas de coqueiro em 1987, com a instalação das primeiras matrizes e, posteriormente, somente em 1995 iniciou a produção de mudas de coqueiro híbrido para fins comerciais. Atualmente, várias pesquisas são executadas na Cohibra visando à realização de experimentos com cruzamentos de diferentes variedades de coqueiro para se verificar qual matriz possui maior produtividade, maior e melhor polpa, melhor água, melhor adaptação ao solo e ao clima. Ao longo desses anos, a Cohibra se tornou a principal empresa do país a fabricar e comercializar mudas de coqueiros híbridos e anões, contribuindo sobremaneira para a dispersão espacial produtiva do coco por todo o território nacional.

\section{COMERCIALIZAÇÃO, AGENTES ENVOLVIDOS E DESTINOS DA PRODUÇÃO}

Depois de realizada toda a produção e a colheita do coco, os frutos são comercializados e destinados a diversos locais. Esses frutos, que passam por uma primeira comercialização, podem ser o coco verde, destinado ao consumo de água de coco - seja in natura seja processada -, ou o coco seco, que pode ser consumido in natura e/ou destinado à produção de coco ralado e derivados. A forma como a comercialização será realizada vai depender tanto do tipo de coco que está sendo encaminhado ao mercado quanto dos agentes envolvidos nessa comercialização. Nesse momento nota-se a existência de dois circuitos espaciais produtivos completamente distintos, já que coco seco e coco verde são produtos diferentes.

De um modo geral, envolvidos na comercialização do coco in natura estão os seguintes agentes: o produtor, responsável pelas decisões de o que e como produzir; o intermediário, primeiro elo entre o produtor e os outros agentes da comercialização; o atacadista, que concentra a produção de vários produtores e intermediários; o varejista, responsável pela comercialização do produto em pequenas quantidades; o consumidor, último elo da comercialização do fruto. Podem ser incluídas ainda nesse grupo as agroindústrias, já que elas adquirem grande parte da produção e estão em constante contato principalmente com os

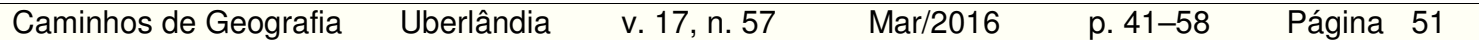


produtores e intermediários. Todos esses agentes citados formam uma complexa rede de fornecimento, comercialização e distribuição de coco, movimentando seu circuito espacial da produção e unindo todas as instâncias produtivas a ele relacionadas.

Entre esses agentes responsáveis pela comercialização do coco, os principais são os intermediários, também conhecidos como atravessadores, possuindo um papel fundamental no circuito espacial produtivo do fruto, agindo "[...] como um elo entre a demanda e a oferta, que não coincidem no tempo, nem em qualidade nem quantidade. Isso lhe dá um papel privilegiado e uma posição estratégica no abastecimento" (SANTOS, 2008b, p. 226). Os atravessadores atuam sobremaneira controlando a quantidade de frutos produzida e o valor pago por essa produção. Além disso, os atravessadores são os responsáveis por decidir para onde a produção será encaminhada e como se dará o escoamento, possuindo, portanto, uma posição estratégica no circuito espacial produtivo do fruto ${ }^{9}$.

Da mesma forma que a comercialização será diferente dependendo do tipo de coco, verde ou seco, a atuação dos atravessadores também será diferente conforme o tipo de produto comercializado. Há atravessadores que somente comercializam coco seco, já outros somente coco verde, e há também aqueles que comercializam os dois tipos. Chegam a existir várias diferenças entre esses atravessadores. Aqueles que comercializam exclusivamente coco seco possuem estabelecimentos fixos localizados nas zonas urbanas dos municípios, para onde levam os frutos adquiridos e onde são feitos a revenda e o escoamento dos mesmos.

No Litoral Oeste percebe-se a existência uma grande quantidade de estabelecimentos de atravessadores de coco seco principalmente em Trairi, Itarema e Itapipoca, que atuam comprando o fruto por toda a região. Municípios especializados na produção de coco verde, como é o caso de Paraipaba, não contam com esse tipo de atravessador. Já aqueles que comercializam apenas coco verde se caracterizam por não possuírem pontos comerciais fixos e por revenderem a produção imediatamente após sua aquisição, uma vez que quanto maior for o tempo de distribuição dos frutos menor será o seu tempo de consumo. Na maioria das vezes são os próprios atravessadores de coco verde que se responsabilizam pela colheita dos frutos, atividade que não fica a cargo de seus produtores.

Todo o coco produzido no Litoral Oeste possui basicamente três destinos principais: as agroindústrias cearenses, a cidade de Fortaleza e os outros estados brasileiros. Além de ser encaminhada a esses três principais destinos, uma pequena parte da produção é consumida pelos próprios produtores, sobretudo o coco seco, que possui um valor de mercado menor que o coco verde. Já outra pequena parte dessa produção é exportada para alguns países ${ }^{10}$, especialmente os Estados Unidos, além de seguir também para o Reino Unido, Alemanha, Canadá, Áustria e Portugal, entre outros. Apesar das exportações do fruto, o foco dos produtores está centrado em abastecer o mercado interno, bastante dinâmico e constantemente aquecido, em virtude da grande quantidade de matéria-prima adquirida pelas agroindústrias ou encaminhada diretamente aos consumidores finais que adquirem esses frutos in natura.

A produção que segue do Litoral Oeste para os outros estados brasileiros é organizada pelos atacadistas/varejistas que firmam contratos prévios com os atravessadores e/ou com alguns produtores, especialmente os maiores. Esses atacadistas/varejistas já possuem compradores certos nos estados para onde a produção será encaminhada. Normalmente a produção já segue para as Centrais de Abastecimento (Ceasas) dos vários estados e para a Companhia de Entrepostos e Armazéns Gerais de São Paulo (Ceagesp), como informaram alguns produtores e atravessadores. Essa produção pode seguir também diretamente para agroindústrias, padarias, confeitarias, supermercados e restaurantes localizados nos estados de destino dessa produção, que adquirem grandes quantidades de coco, seja verde seja seco.

A partir de entrevistas realizadas com inúmeros agentes inseridos no circuito espacial produtivo de coco, constatou-se para quais principais estados a produção estava sendo encaminhada. $O$ principal destino do coco (verde e/ou seco), citado pela maioria dos entrevistados, é o estado

\footnotetext{
${ }^{9}$ Posição essa contestada pela grande maioria dos produtores de coco, insatisfeitos com a forma de atuação dos atravessadores, que agem monopolizando a comercialização dos frutos.

${ }^{10}$ Conforme apontam os dados obtidos junto ao Ministério do Desenvolvimento, Indústria e Comércio Exterior (MDIC).
}

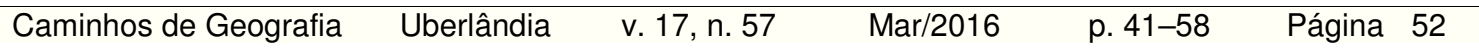


de São Paulo, seguido do Piauí e do Maranhão, que aparecem como os principais destinos do coco cearense. Uma parte importante da produção seguia ainda para Sergipe, Alagoas, Rio Grande do Norte, Pará, Minas Gerais, Rio de Janeiro, Paraná, Santa Catarina, Rio Grande do Sul e Goiás, como se pode ver no mapa abaixo (Figura 5).

Figura 5. Principais destinos do coco produzido do Litoral Oeste do Ceará.

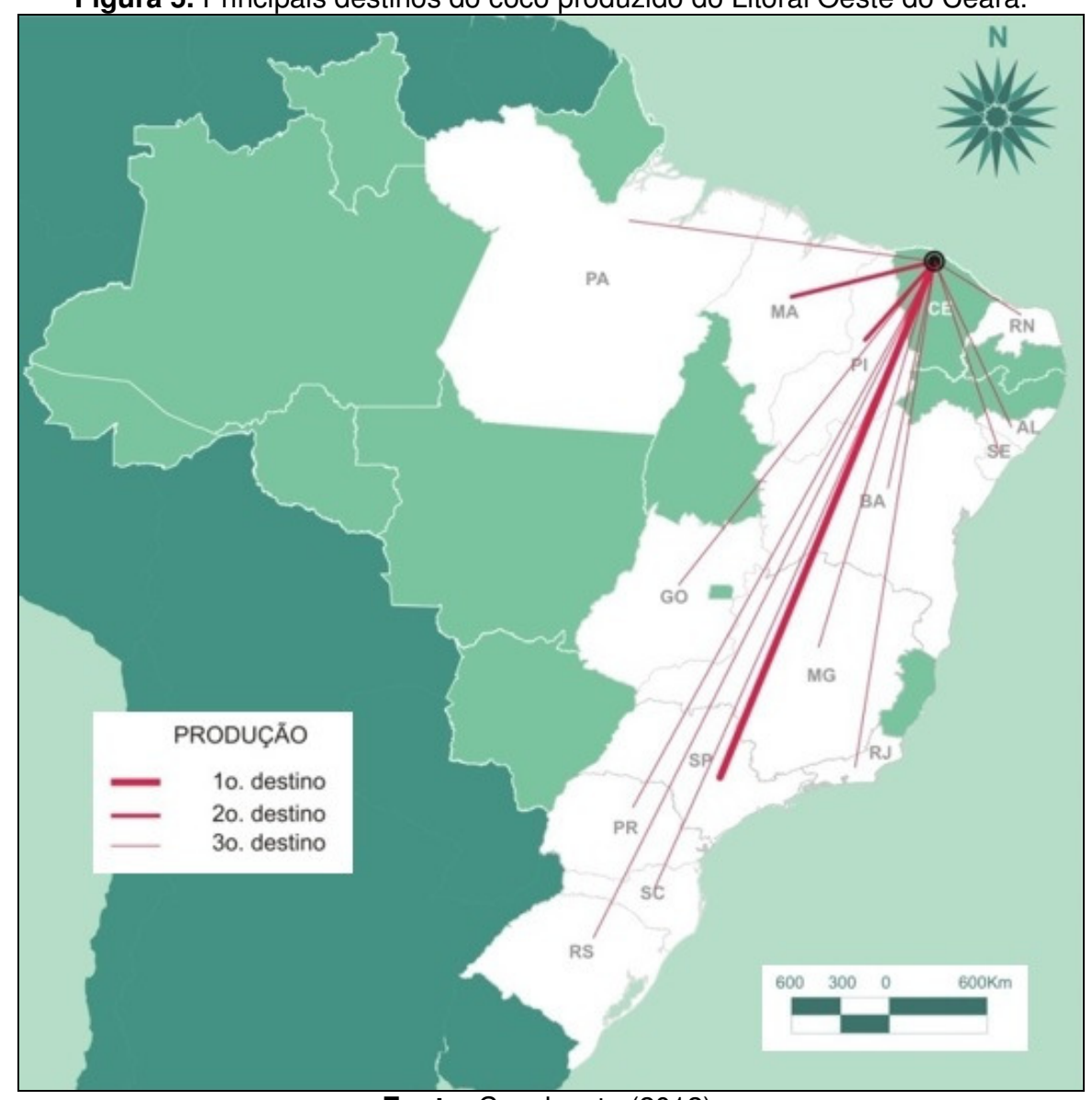

Fonte: Cavalcante (2012).

Nota-se, no referido mapa, que aqui o caminho é inverso ao observado na distribuição dos insumos (Figura 4), demonstrando o papel do Litoral Oeste enquanto fornecedor de matériaprima (o coco) e adquiridor de bens industrializados (os insumos e implementos). Isso revela principalmente que a partir da análise de um circuito espacial produtivo é possível visualizar a situação relativa dos lugares, ou seja, a definição da respectiva fração de espaço em função da divisão do trabalho sobre o espaço total do país, conforme sugere Santos (1986, p.130), revelando também a posição hierárquica desses lugares perante as redes de produção globalizada (ELIAS, 2003), que agem unindo espaços e agentes em um só movimento.

\section{PROCESSAMENTO INDUSTRIAL E ATUAÇÃO DAS AGROINDÚSTRIAS DO COCO}

Dentre os estabelecimentos agroindustriais existentes nos municípios do Litoral Oeste cearense sobressaem-se especialmente aqueles especializados no processamento de derivados do coco, as agroindústrias do coco. Nessa região existem inúmeras dessas empresas, de vários portes e que fabricam os mais variados produtos. A principal e maior delas é a Ducoco, que apresenta um grande porte, mas há também a Paragro, a Adel Coco, a Dicoco, a Monteiro Cocos, a Edcoco e a Itcoco, todas de porte médio. Há ainda várias outras empresas que fazem o processamento da água de coco e/ou produzem coco ralado e leite de coco, que se caracterizam por ser empresas familiares de porte muito pequeno. Juntas, todas essas agroindústrias adquirem uma quantidade importante de coco todos os dias, muitas das vezes adquirida apenas via atravessadores, que a adquirem com produtores localizados principalmente na própria região. 
Todas as principais agroindústrias, com exceção apenas da Ducoco, foram fundadas nos últimos 10 anos, e isso está diretamente associado ao incremento do cultivo de coco no Ceará, que passou a despertar a atenção de diversas empresas especializadas no processamento de subprodutos originados do fruto, principalmente a água de coco (como é o caso da Paragro e da Edcoco) e o coco ralado (especialidade da Dicoco, da Adel Coco, da Itcoco e da Monteiro Cocos). Além disso, todas essas agroindústrias vêm investindo pesado também na produção agrícola dos frutos, adquirindo fazendas visando garantir uma maior autonomia no suprimento de suas matérias-primas, somando-se às empresas agrícolas já existentes, que juntas atuam no sentido de expandir consideravelmente um formato mais empresarial no cultivo de coco, não observado com muita intensidade até o início dos anos 2010.

Dentre as principais agroindústrias instaladas no Litoral Oeste o destaque vai para a Ducoco, uma empresa "multifuncional e multilocalizada" (CORRÊA, 1992), em atuação desde 1982, configurando-se atualmente como a segunda maior e mais importante empresa do ramo de subprodutos do coco de todo o país, atrás apenas da alagoana Sococo. Atualmente, a Ducoco se espacializa por várias partes do território nacional, atribuindo usos aos lugares de acordo com suas necessidades e capacidade produtiva. Essa empresa conta com duas grandes unidades industriais, uma em Itapipoca (CE) e outra em Linhares (ES), além de três centros de distribuição localizados nessas duas cidades e também em Barueri (SP), que distribuem os produtos de suas fábricas às diversas partes do país. E apesar da Ducoco ser uma empresa cearense, sua sede administrativa localiza-se na cidade de São Paulo (SP), na região da Avenida Paulista.

O portfólio dessa empresa conta com quase cem produtos, distribuídos em três marcas (Ducoco, Menina e Frutop), como leite de coco, coco ralado e água de coco, além de sobremesas em geral, como gelatinas, pudins, manjares e quindins, produzindo também alguns tipos de chás, demonstrando que sua produção vai muito além de produtos oriundos do coco. Há na Ducoco uma especialização produtiva entre suas unidades fabris, uma vez que a fabricação dos produtos é segmentada, onde a unidade de Itapipoca produz apenas água de coco e leite de coco em caixinhas, além de processar todo o coco ralado, que somente depois é encaminhado para a unidade de Linhares para dar origem aos outros produtos. Atualmente a Ducoco tem como carro-chefe o processamento de água de coco, armazenada em caixinhas de papelão e voltadas para abastecer os promissores mercados nacional e, sobretudo, internacional, conforme foi relatado em visita a essa empresa.

Além de se configurar como uma importante empresa agroindustrial, com atuação em todo o Brasil, a Ducoco é também a maior empresa agrícola de produção de coco instalada no Ceará. Possui ao todo 4.000 hectares cultivados com aproximadamente 300 mil coqueiros, distribuídos em sete fazendas localizadas nos municípios de Itapipoca, Itarema e Camocim, todos no Litoral Oeste, tendo se tornado a maior proprietária de terras cultivadas com coco em todo o Ceará, e também uma das maiores do país, produzindo uma enorme quantidade de frutos diariamente. Além disso, a Ducoco é uma das maiores empresas a possuírem terras nesse estado, detendo 10 mil hectares declarados, muitos dos quais ocupados por áreas de mata nativa e dunas que funcionam como reserva de valor para futuros investimentos.

Assim, de todas as empresas que atuam no setor do coco no Ceará, sejam elas agrícolas e/ou agroindustriais, a que tem o maior poder de "alienação territorial" (SANTOS, 2003) é a Ducoco, não apenas por se tratar da maior empresa em atuação, mas por ter a capacidade de realizar as seguintes ações, entre outras: embolsar grandes investimentos do Estado e de instituições financeiras; controlar grandes extensões de terras e hectares cultivados; movimentar diariamente importantes quantidades de matérias-primas, produzidas ou não pela empresa; empregar centenas de funcionários, tanto na produção agrícola quanto industrial; gerir unidades produtivas geograficamente dispersas; adquirir a produção de inúmeros produtores e atravessadores; dinamizar a economia urbana dos municípios onde estão instaladas suas unidades produtivas; promover fluxos diários de trabalhadores para as fazendas e para a fábrica; controlar uma grande rede de distribuição de seus produtos.

Ao executar simultaneamente todas essas atividades, a Ducoco influi de maneira crucial na organização espacial e na regulação territorial das áreas onde atua. Além disso, a Ducoco é responsável por gerar impactos das mais diversas naturezas, como, por exemplo, desencadear

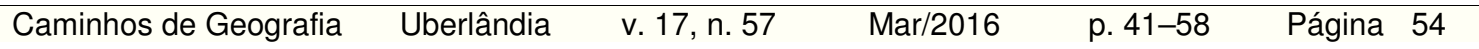


regulação territorial, entre outros processos. Ficou evidente, ainda, que o circuito espacial da produção do coco oriundo do Litoral Oeste do Ceará foge aos clássicos modelos lineares dos circuitos produtivos, já que definitivamente aqui a linearidade não é a regra, e sim a exceção.

\section{AGRADECIMENTOS}

O autor agradece ao Conselho Nacional de Desenvolvimento Científico e Tecnológico (CNPq) pela bolsa de Iniciação Científica (IC), que custeou a realização da pesquisa aqui apresentada.

\section{REFERÊNCIAS}

ARACRI, L. A.; MOREIRA, F. S. Considerações metodológicas sobre o estudo do circuito espacial da bovinocultura de corte em Mato Grosso. In: BERNARDES, J. A.; ARACRI, L. A. (Orgs.). Espaço e circuitos produtivos: a cadeia carne/grãos no cerrado mato-grossense. Rio de Janeiro: Arquimedes, 2010. p. 75-88.

ARROYO, M. Território brasileiro e mercado externo: uma leitura dessa relação na virada do século XXI. In: SOUZA, M. A. (Org.). Território brasileiro: usos e abusos. Campinas: Edições Territorial, 2003. p. 428-457.

CAVALCANTE, L. V. Os circuitos espaciais e os círculos de cooperação da produção de coco no Litoral Oeste do Ceará. 2012. Monografia (Geografia) - Fortaleza, CE: UECE.

La restructuration de la production de noix de coco au Brésil: enjeux et défis. Le cas des nouvelles dynamiques socio-spatiales du Périmètre Irrigué Curu-Paraipaba. 2014. Mémoire de recherche (Master en Géographie) - Paris: Université Paris 1 Panthéon Sorbonne.

A nova geografia do coco: reestruturação produtiva, territorialização do capital e dinâmicas socioespaciais. 2015. Dissertação (Mestrado em Geografia) - Fortaleza, CE: UECE.

CAVALCANTI, J. S. et al. Transformações recentes nos espaços da fruticultura do Nordeste do Brasil. In: ELIAS, D.; PEQUENO, R. (Orgs.). Difusão do agronegócio e novas dinâmicas socioespaciais. Fortaleza: Banco do Nordeste, 2006. p. 117-150.

CASTILLO, R.; FREDERICO, S. Espaço geográfico, produção e movimento: uma reflexão sobre o conceito de circuito espacial produtivo. Sociedade \& Natureza, v. 22, p. 461-474, 2010.

CONTEL, F. B. Os sistemas de movimento do território brasileiro. In: SANTOS, M.; SILVEIRA, M. L. O Brasil: território e sociedade no início do século XXI. 5. ed. Rio de Janeiro: Record, 2003. p. 357-374.

CORRÊA, R. L. Corporação, práticas espaciais e gestão do território. Revista Brasileira de Geografia, Rio de Janeiro, n. 54, p. 35-41, 1992.

ELIAS, D. Globalização e agricultura. São Paulo: EdUSP, 2003.

Agronegócio e desigualdades socioespaciais. In: ELIAS, D.; PEQUENO, R. (Orgs.). Difusão do agronegócio e novas dinâmicas socioespaciais. Fortaleza: Banco do Nordeste, 2006. p. 25-82.

FREDERICO, S. O novo tempo do Cerrado. São Paulo: Annablume, 2010.

SILVA, J. G. Tecnologia e agricultura familiar. 2. ed. Porto Alegre: Editora da UFRGS, 2003.

SANTOS, M. Espaço e método. São Paulo: Nobel, 1985.

. Os circuitos espaciais da produção: um comentário. In: SANTOS, M.; SOUZA, M. A. (Orgs.). A construção do espaço. São Paulo: Nobel, 1986. p. 121-134.

. Metamorfoses do espaço habitado. 3. ed. São Paulo: Hucitec, 1994.

Técnica, espaço, tempo. 2. ed. São Paulo: Hucitec, 1996.

Modo de produção técnico-científico e diferenciação espacial. Revista Território, Rio de Janeiro, ano 4, n. 6, p. 5-20, 1999. 
Por uma outra globalização. 10. ed. Rio de Janeiro: Record, 2003.

Por uma geografia nova. 6. ed. São Paulo: EdUSP, 2008a.

. 0 espaço dividido. 2. ed., 1. reimpr. São Paulo: EdUSP, 2008b.

A natureza do espaço. 4. ed. São Paulo: EdUSP, 2009.

SANTOS, M.; SILVEIRA, M. L. O Brasil: território e sociedade no início do século XXI. 5. ed. Rio de Janeiro: Record, 2003. 